Scaffolding Homework for Mastery : Engaging Parents

Dr Janet Goodall, EdD

Swansea University

J.s.goodall@swansea.ac.uk

Word count: 8801 


\section{Scaffolding Homework for Mastery : Engaging Parents}

The value of parental engagement in the learning of children and young people has repeatedly been shown to be of value in the literature, and in practice (Fan and Williams 2010; Fan and Chen 2001a; Jeynes 2012; Jeynes 2014). One of the ways many parents feel they can be involved in their children's learning is through support with homework, and homework forms a ubiquitous part of schooling in most systems. However, parental engagement with homework has been shown to be problematic in the literature (Medwell and Wray 2019; Cooper, Robinson, and Patall 2006). This paper combines the literature on parental engagement, with that on both the effectiveness and purposes of homework and that on the importance of mastery orientations for young people, to argue that the effective forms of parental engagement in young people's homework will be engagement that supports and leads to mastery orientations on the part of children. The paper includes a schematic for this engagement and concludes with principles for designing homework tasks.

Keywords: Parental engagement; homework; mastery orientations

Homework forms an important element of the experience of schooling for young people in the UK (Xu 2013) and therefore, for their families.

In the US, there is a suggestion of a formula to determine the amount of homework which should be set for children: 10 minutes a day, multiplied by their grade level (Cooper, Robinson, and Patall 2006). This would mean, for a 6 year old in first grade, 10 minutes a night, and for a young person in their final year of schooling (grade 12), two hours of homework a night. Yet research findings show that even primary students are subject to much greater loads than this recommendation would suggest (Pressman et al. 2015).

There are no formal guidelines for the amount of homework required for children of various ages in the UK (not since 2012, (BBC News Online 2012)). Recent research has found that 50\% of female students in England in year 9 (approximately 13- 14 years old) were likely to spend at least 3 hours on homework a week, while their $43 \%$ of their male 
counterparts were also spending that amount of time on homework (Baker et al. 2014). This would suggest that the burden of homework on young people (and their families) is not inconsiderable. International research would suggest that four hours of homework a week is related to improvements in outcomes; more than this, however seems to have a 'negligible impact on performance' (Organisation for Economic Co-operation 2014, , 2) (See also: Organisation for Economic Co-operation Development 2011). Overall, however, it has become clear that the simple measure of time spent is not helpful in relation to understanding the efficacy of homework practices (Xu and Corno 2003).

This article will examine the literature around the purposes of homework, and align this with the literature around parental engagement ${ }^{i}$ with learning, and combine the two to argue that homework, when well-conceived and completed, can form an essential element in a scaffold for mastery orientations for young people, supporting their self-concepts as learners. The literature reviewed has been used for its relevance to the subject of homework and particularly to that of mastery orientations; this literature forms part of a much wider body of work relating to mastery and the concepts of, for example, self-regulation and achievement (Komarraju and Nadler 2013), the impact of understandings of the control one exercises over areas of life (Cobb-Clark, Kassenboehmer, and Sinning 2016). In the first instance, the article will examine homework in relation to the three stakeholder groups most involved: students, families and teachers, and the purposes of homework for these groups. Parental engagement and parental self-concept will be examined to lead into a discussion of how homework can be used to support mastery orientations for young people. The article offers new, and more useful definitions of both homework, and homework for mastery, advancing the theory and definitions in the field. 


\section{Homework for students, school staff and families}

\section{Homework and students}

In spite of the fact that students are most directly affected by the process of homework, their voice is strangely absent from many of the debates around this subject. Coutts (2004) offers this voice, showing that for homework to be of value to students, all parties (parents, students and teachers) understand why homework has been assigned, and what its intended outcome should be.

Coutts highlights aspects around homework that, though important, do not tend to appear in the rest of the literature. For older students (middle and high school) the social aspect of learning in school is important, and is generally missing from homework; students work with friends and colleagues in school and alone, for the most part, once school has finished for the day. Coutts also notes that students who struggle to complete work in class tend to view homework that requires completion of that work at home as a penalty (2004).

It would be a mistake to assume that the experience of homework is the same for all students. For example, in a sample of year 9 students, 66\% of students in the UK identifying as Indian reported that they were likely to spend 3 or more hours a week on homework, while only 36\% of students identified as Bangladeshi spent that amount of time. There are also reported differences related to the social and economic status of students (SES): $14 \%$ of students in the most deprived areas spend no time on homework while only $5 \%$ report the same in the most affluent areas. In those areas, $58 \%$ of students reported spending 3 or more hours and only 35\% at the other end of the scale. There are also differences related to schools; 53\% of children in schools rated Outstanding by Ofsted did 3 or more hours of homework and only 30\% in inadequate rated schools (All information from Baker et al. 2014). . Internationally, 'students who attend socioeconomically advantaged schools tend to spend two hours per week longer on this [homework] than students who attend disadvantaged 
schools (Organisation for Economic Co-operation Development 2013). Students who do not already have knowledge in the given area may also spend more time on homework, simply to complete it to the same standard as their peers who had more knowledge to start with (Hallam 2006). All of this may account for why simple time spent on homework is not a good measure of its effectiveness.

The reported differences between groups of students, particularly the information about students from different backgrounds and differently graded schools are quite troubling, particularly if we accept that, overall, homework completion may be of value to students. If this is the case, and if it is also the case that students who come from more affluent homes do more homework, it may be that homework is another element that acts as a wedge to keep the SES related gap in achievement open, or at least prevent it from narrowing substantially. The OECD suggests that homework 'may also reinforce socio-economic disparities in student achievement'(Organisation for Economic Co-operation 2014, , 3). If we are serious about narrowing the gap - or better, if we are serious about fulfilling the education debt (LadsonBillings 2006), then any changes to policy and practice around homework must not only take account of the impact different backgrounds have on student achievement, but seek to redress them. Otherwise, we risk continuing to support those who already succeed while exacerbating the difference in achievement based on background (Borgonovi and Montt 2012; See also Jeynes 2012).

\section{Homework and families}

Overall, the research literature is quite clear, and has been for some time, that parents' engagement in their children's learning is of value (Desforges and Abouchaar 2003; Fan and Chen 2001b; Jeynes 2007, 2005; Jeynes 2012). In a study looking at intervention programmes for students in urban schools, Jeynes found the largest effect sizes for programmes which supported parents to read with their children, and the second largest effect 
from programmes which emphasised partnerships between parents and school staff. These findings support the contention that what matters in terms of parental engagement is engaging in learning, rather than engagement with the school directly (Goodall and Montgomery 2013b).

Yet, in saying this, families have reported that homework can form a significant arena for conflict (Pressman et al. 2015; Goodall and Johnston-Wilder 2015; Carmichael and MacDonald 2016; Ofsted 2018). Conflict can arise from many causes, and it is interesting as we shall see below that parental over involvement and excessive monitoring of homework are related to negative outcomes for pupils as these are actions which might well lead to conflict in the home.

In an international survey, parents in the UK reported spending less time with homework than parents in many other countries (and, in general, it was found that parents in emerging economies spent more time than parents in established economies). Overall, 11\% of UK parents of children between the ages of 4 and 18 spent 7 or more hours a week helping with homework, 14\% between 4 and 7 hours, 29\% (the largest grouping) between 1 and two hours, $4 \%$ less than one hour and 23\% reporting spending no time helping with homework ${ }^{\mathrm{ii}}$. Worldwide, parents with higher levels of education were likely to spend more time with homework than parents with only a primary level of education. Parents reported spending the most hours a week (7) with children between the ages of 8 and 11, with only slightly less (6.9) with children between 4 and 7, and the lowest amount, which was still 6.2 hours per week, with students at the upper end of the age banding, 16 - 18. Interestingly, considering the frequent discussions of homework in the popular press, $63 \%$ of parents in the UK reported that they felt they were sending the 'right amount' of time helping with their children's education (which may, of course, be wider than the concept of helping with homework) (Varkey Foundation 2017). 
Globally, 52\% of parents report that not having enough time is the greatest barrier to helping with their children's learning, with lack of information about how to help or help received from other sources in second and third place (32 and 30\% respectively). Other research also suggests that parents often feel unable to help with their children's homework (Epstein and Van Voorhis 2001; Peters et al. 2008; Kay et al. 1994). It is possible, however, that this may be because parents are concentrating on the content, as so much has changed since parents were themselves in school (Kay et al. 1994) rather than because they are not showing an interest in learning. Only 19\% of parents in the global survey felt that helping with their child’s learning was not their place. (Varkey Foundation 2017).

Overall, for parents and families, homework seems to provide a point of connection with their children's learning but is one that can be problematic.

\section{Homework and teachers}

Homework figures largely in teachers' lives as well as students'; it is a part of teachers' professional work (Epstein and Van Voorhis 2001; Independent Teacher Workload Review Group 2016). Preparing, setting, discussing, and marking homework does not form a separate category in surveys on teachers' workloads, but it can be closely aligned to the general responses teachers give about marking and assessment.

It has become increasingly obvious that school staff in the UK, and elsewhere, face workloads which are unsupportable in the long run; 93\% of teachers responding to a recent survey said that workload was at least a fairly serious problem, and over three quarters of respondents were dissatisfied with the hours they worked (Higton et al. 2017). In both the primary and secondary phases of schooling, over $70 \%$ of teachers felt that too much of their time was spent in marking or correcting students’ work (Higton et al. 2017). Assessment and marking policies were felt to be among the top five reasons for high workloads by $72 \%$ of respondents in a recent survey (NASUWT 2018). This would argue that it is important that 
homework is addressed directly as a matter of teacher workload issues, and also that schools and school staff should be clear not only about the purposes of homework (eg why it is assigned) but also the best ways to support those hoped-for outcomes (NASUWT 2018) ${ }^{\mathrm{iii}}$.

\section{Effectiveness of homework}

Homework may be defined as school oriented work to be performed by students outside the classroom (See, among many others: Xu 2010; Warton 2001; Fan et al. 2017). ${ }^{\text {iv }}$ It can also be understood as a home-based method of familial involvement in children's learning (Gonida and Cortina 2014). It is interesting that neither of these definitions mentions the purpose of homework, or its outcome, and that one of them is focused on the learner and the other, on the family. Regardless of how it is defined, however, it is clear that homework impacts on the lives of school staff, students and the families of both, on a weekly, if not daily, basis.

There is little agreement in the research literature about the value of homework; 'The effect of homework on student achievement is a matter of dispute’ (Fan et al. 2017, , 174); recent overviews of the literature support this. Work on the effectiveness of homework has, however, been done (Fan et al. 2017; See, for example, Warton 2001; Patall, Cooper, and Robinson 2008; Cooper, Robinson, and Patall 2006; Hallam 2006). While the impact of homework is generally favourable, the results of research are quite nuanced: the impact can depend on a number of factors, such as the subject (Bas, Senturk, and Cigerci 2017), the age of the young person involved and (importantly for our purposes here) the engagement of parents (Carmichael and MacDonald 2016; Patall, Cooper, and Robinson 2008). Medwell and Wray (2019)report that the effects of homework seem to be much stronger in secondary school than in primary (Patall, Cooper, and Robinson 2008; Fan et al. 2017; Madjar, Shklar, and Moshe 2016; Pomerantz, Ng, and Wang 2006; See also: Hallam 2006). Interestingly, it seems that one factor which is of value is not the time spent on homework, but rather the 
effort students put into homework (Trautwein 2007). Although the impact of time spent may differ between children depending on how they approach homework, effort still seems to be more important than a simple measure of time spent (Flunger et al. 2015; Núñez et al. 2015); time is, however, much easier to categorise and quantify for research.

We now examine the purposes of homework, for the different stakeholders. It is interesting that some of the purposes proposed for homework (such as school-parent communication, and protecting the school from the harsh judgements that might arise from not assigning homework, see below) seem to have little direct relevance to students (Xu 2010; Warton 2001), even though they are the ones most directly affected by having to complete the work. We need to question these purposes, particularly in light of the amount of time some young people devote to their homework.

\section{The (perceived) purposes of homework}

All of this, however, begs the question of what we want homework to do - what is its purpose? Since it forms so much a part of teachers' and students' lives, and since it impinges so much on family life, surely we need to be clear not only about the purpose of homework but how specific instances of homework are aligned to, and set out to accomplish, that purpose (Coutts 2004). The literature, based on school practice and report would seem to suggest three orientations for homework, that is, homework can be seen to serve the purposes of the actors mentioned above. However, it should be noted that as (Warton 2001) points out, the main voices highlighted in the literature are those of school staff, with parents coming a far second and pupil voice, eg those arguably most affected by the imposition of homework, are rarely heard(Coutts 2004; Xu and Yuan 2003). There are purposes oriented toward the school, those oriented toward the family and those oriented toward the pupil. We will take a synthetic look at the ideas within these categories Error! Reference source not found. shows how these categories arise in the literature. 
It should be noted that many instances of homework can fulfil more than one purpose (Epstein and Van Voorhis 2001; Xu 2010) (just as many other interventions in schooling can serve more than one purpose). It is also possible that the same experience of one piece of homework could have both positive and negative outcomes: e.g. a young person might learn content (positive) while at the same time experiencing heightened tension in the home (negative) (Patall, Cooper, and Robinson 2008; Goodall and Johnston-Wilder 2015).While it has been suggested that marking overall (and one would assume, therefore, homework) should be oriented to support student's achievement (Independent Teacher Workload Review Group 2016), this need not mean that the only purpose for homework should be oriented toward the student, at least in the first instance (eg including parents in homework may seem to be oriented toward adults, but will ultimately benefit students). However, it would seem to be difficult to make an argument for any imposition of homework which is not, ultimately, oriented toward the benefit of the student's learning.

\section{Student oriented purposes}

...there is a critical need to pay close attention to purposes of homework as perceived by students. Specifically, there is a need to help students inject personal meaning into their homework, viewing it as an important vehicle for reinforcing school learning and for developing a sense of responsibility (Xu 2013, , 100)

It would seem obvious that the student oriented purposes of homework should be paramount; students are the ones undertaking the work, and their learning is, presumably, the reason for assigning the work in the first place. Homework should be oriented toward supporting student learning, both in a narrow sense (related to specific content) and more broadly (related to the skills and attitudes which will benefit them in the future as well as the present) (Independent Teacher Workload Review Group 2016). Although the subject was marking overall (of which marking homework is a subset), what the Independent Review 
Group says still applies: it should 'serve a single purpose - to advance pupil progress and outcomes’ (Independent Teacher Workload Review Group 2016, , 8).

Homework can support student learning in both what might be called immediate and proximal manners. One simple way homework is proximally oriented toward students is that it extends the amount of time spent on schoolwork, beyond the school day; this could be in the form of practicing what has been done, extending current work or preparation for what is to come (Epstein and Van Voorhis 2001). That this should feature in students' lives is not surprising; what may be of interest is the impact that work outside of school can have (Save the Children 2013).

Students may also be given work aimed at getting them to interact with other students (Epstein and Van Voorhis 2001). Middle school students, in particular, have been clear that one of the greatest perceived costs - that is, reasons they dislike - homework is that it is a solitary endeavour, for the most part, which separates them from their peer group (Coutts 2004); so it would seem that homework which aims to connect students with one another, and continue the social learning which takes place in school, could be of value.

A further, more distant purpose of homework for students - is the inculcation of skills and attitudes toward school work (Medwell and Wray 2019) and to work overall, as some parents have reporting perceiving homework as preparation for working life (Corno and Xu 2004). This purpose of homework - either explicitly stated or not (e.g. teachers assume that certain things will result from the practice of assigning homework), is developmental for students. The assumption is that in undertaking work related to school, outside of school, students will develop skills in time management, study skills and increase their ability to self regulate (Epstein and Van Voorhis 2001; Goodall and Johnston-Wilder 2015; Xu 2013), including taking on of responsibility to complete the work set; these are elements which might be called the ‘intrinsic’ purposes of homework (Coutts 2004). 
Coutts (2004) raises the interesting point of who is seen/considered to be responsible for ensuring homework is completed. If parents are expected to sign a card, register or book to show the work has been done, what message does this send to the young person actually doing the work? Does this sort of parental involvement actually support children's moves toward self regulation or taking responsibility for their own work? Coutts' research, which is of interest because of its concentration on the voices of students themselves, goes on to point out that particularly younger learners may complete homework not $a$ s a punishment (a reason suggested by some authors) (Epstein 1983), but rather to avoid punishment or at the least, to avoid disappointing adults such as teachers (Coutts 2004). While these are student-oriented reasons for homework, they seem to have little alignment with learning.

\section{Family oriented purposes}

The research is clear that when parents are involved with children's homework, the general outcomes are good (Patall, Cooper, and Robinson 2008). This is not, however, a panacea: overall, the outcomes may be beneficial, but there are conditions in which parental engagement with young people’s homework seems to be detrimental to learning (Patall, Cooper, and Robinson 2008), quite possibly because, in at least some of these cases, parents have become, or become more involved precisely because their children were not doing well in their studies (Cooper, Lindsay, and Nye 2000). On balance, however, seeking to involve parents and families does seem to be of value to student's learning.

Some authors suggest that homework can be assigned to increase communication within families (Epstein and Van Voorhis 2001). This is an interesting reason for assigning homework but it does raise the question of whether this is something that schools should be doing, is it within their remit to attempt to change relationships within homes (Goodall 2019)? And if so, on what basis is this being done? It is worth recalling the criticisms and critiques that have been made of the views that school staff may hold of families, particularly 
families who differ from school staff in terms of culture, ethnicity, or other elements of their lives (Goodall 2019; Crozier 2001; Crozier 1999), in spite of evidence of the value of parental engagement (see above) and, for example, the high aspirations parents hold for their children \{Gorard, $2012 \# 4196$ \} \{Treanor, $2017 \# 23456$ \}. Staff perceptions of relationships in the home, and the amount of help or support that young people receive at home, are often far from accurate (Crozier 1999; Crozier 2001; Vincent and Tomlinson 1997; Vincent 2001), which could in turn lead to interventions which are not fit for purpose.

Schools may also assign homework to young people as a means of furthering relationships between the school and parents, or keeping parents informed about developments in school (Epstein and Van Voorhis 2001; Van Voorhis 2004). Again, it seems legitimate to question whether or not imposing work on young people is a reasonable means of attaining these ends. It would seem that the ultimate end, reason for the assignment of homework must always be to further and support the learning of the young people who are to carry out the work. It may be that the homework also serves proximate causes, such as being a means of communication between school and home - but such a purposes would seem to be legitimate only in so far as it serves the ultimate aim of student learning. As noted above, however, homework may have more than one purpose: creating this kind of dialogue between staff and parents may be a second, but should not be a primary purpose of imposing work on young people (and probable marking, on teachers).

\section{School oriented purposes}

Schools may be perceived to be more successful if they assign more homework (Medwell and Wray 2019; Xu and Yuan 2003), which can be a powerful motivator for staff. According to Epstein and Van Voorhis, there is a perception that good schools assign homework and that good students do homework (Epstein and Van Voorhis 2001). School staff may be expected by outside authorities to assign homework or certain amounts of 
homework (Epstein and Van Voorhis 2001); this is, however, no longer the case for the UK as a whole.

Van Voorhis (2004) considers a 'political' function of homework and agrees that it has what might be considered an outward facing function, that it 'signals parents and the public that a school has rigorous academic standards and expectation for student work' ( $\mathrm{p}$ 208). However, as shown above, not all students engage in the same amount of homework, and students who are already more likely to succeed, seem to do more homework. Increasing parental engagement with homework, without taking into account such nuances, risks increasing the gap in achievement between young people from different backgrounds, rather than supporting those at most risk of failing (Borgonovi and Montt 2012).

Research has shown value in training parents to help with homework (Patall, Cooper, and Robinson 2008; Epstein and Van Voorhis 2001). While programmes such as TIPS have been shown to have statistically significant outcomes in terms of raising achievement, these outcomes fall short of those which arise from initiatives which come from parents themselves (Jeynes 2012). In fact, the literature shows that the largest effect sizes from programmes to support parents' engagement with learning come from helping parents to share reading with their children, and to work in partnership with school staff, around the child (Jeynes 2012), rather than directly teaching content. As mentioned above, the aim of supporting parental engagement with learning is to produce a partnership between families and schools, but this does not mean that all parties have to undertake the same actions.

It is also interesting that among the training programmes reviewed by Patall et al, the one that had a negative outcome was the one that trained parents to monitor homework (rather than work with the young person) (Patall, Cooper, and Robinson 2008), suggesting that setting up an adversarial, monitoring culture in families is not as helpful as supporting 
interaction and working together (yet it is interesting that the TIPS programme, mentioned above, includes this element (Epstein and Van Voorhis 2001)).

Schools may also use homework as a way of interacting with families, as a means of communication with parents and other family members (Epstein and Van Voorhis 2001). This may include letting parents know what is being taught, how children are getting on, and how they as family members can help (Epstein and Van Voorhis 2001). Again, these are laudable aims, but it is far from clear that increasing the burden of work on both students and staff (in doing and marking the homework) is the most efficient means of communication with families.

This article argues that the only reason homework should be assigned is to support the learning of young people, particularly by giving them the skills and attitudes that will support further learning (Medwell and Wray 2019; Cooper, Lindsay, and Nye 2000).

As noted above, the original definitions of homework do not include anything about purposes or outcomes. I would suggest a new definition: "Homework may be defined as school oriented work to be performed by students outside the classroom, which has a clear, stated aim to support learning, either in terms of content, skills or attributes oriented toward learning”. We now move on to discuss those skills and attributes, under the head of mastery orientations toward learning.

\section{Mastery Orientations}

An orientation towards mastery is defined as an orientation towards developing one's competence via a focus on understanding and skill acquisition, whereas an orientation towards performance is an orientation towards demonstrating one's competence or avoiding the demonstration of lack of competence via a focus on gaining favourable judgments and higher school grades compared with others or on avoiding unfavourable judgments (for reviews, see, e.g., Ames, 1992; Elliot, 2005; Kaplan, Middleton, Urdan, \& Midgley, 2002). (Gonida and Cortina 2014, , 380) 
Research has shown, to put it colloquially, that children who don’t believe they can, don't - that is, young people who believe they are not able to achieve in school, often don't achieve, even when other indicators suggest that they should be able to do so (Rogers et al. 2014).

Mastery and performance orientations are often linked and contrasted in the literature, as in the quotation above. This paper suggests moving children away from an orientation on external validation for their learning processes (which would be evident, for example, in asking parents to check and monitor homework), to an orientation on(Kurt and Taş 2019) internal validation, through increased confidence in their abilities to learn, and the acquisition of and confidence in the skills needed to do so. Children with a 'mastery orientation' toward learning will value learning for its own sake; they are also likely to structure their work effectively (Kurt and Taş 2019). This is not to deny the importance or validity of external measures of learning, such as marks, grades and exam results. However, it is to shift the balance of importance so that children come to see learning as a lifelong process, a view which will serve them well in further studies as they age.

Moreover, this paper argues for a move toward greater autonomy for young people in the completion of homework, which is a concomitant part of mastery ordinations. Research has shown a correlation between parental support for autonomy and higher achievement on standardized tests and in class grades (Grolnick et al. 1997; Cooper, Lindsay, and Nye 2000), while greater active involvement by parents in homework was associated with the opposite effects (Cooper, Lindsay, and Nye 2000)\{Dettmers, 2019 \#23663\}.

The term, 'mastery orientation' may be understood to encompass a number of different ideas. Among these is what Fan, Williams et all term 'intrinsic motivation,' which 'refers to the willingness of individuals to engage in and complete academic tasks for their own sake' (Fan, Williams, and Wolters 2012, , 22); one might liken this to enjoying learning 
for learning's sake, or seeing education as a process throughout life, rather than a discreet entity (Dewey 1897; Goodall 2017b). Intrinsic motivation seems to be best supported through role construction and self-belief, rather than external rewards (Deci, Koestner, and Ryan 2001); students who are intrinsically motivated seem to be more engaged in school work, are more likely to persist in the face of difficulties and have higher achievement than students who rely on extrinsic motivation (e.g. rewards)(Kurt and Taş 2019). Young people are more likely to ask for help with their work when their teachers emphasise mastery orientations, such as the value of learning for its own sake (Du, Xu, and Fan 2016).

Young people were more likely to seek appropriate help with homework if they had a mastery orientation toward their work (Du, Xu, and Fan 2016); this may seem antithetical, that young people who have a positive belief about their abilities were more likely to seek help, but this would argue that having those beliefs can result in having the confidence to seek help when needed. If children and young people are able to seek help when they need it, and, importantly, are trusted to do so by those around them, then it would seem likely that there will be fewer instances of the over involvement of parents in homework which we have seen can be detrimental for children's long term achievement. Research has found that children who are not confident about their abilities are especially able to increase their feelings of competence when their mothers provide support for autonomy and mastery (Pomerantz, Ng, and Wang 2006).

There is an obvious connection between how students are motivated and how parents relate to children's studies and school work; when parents (mothers in this case) used mastery oriented technics to support their children, such as encouragement to persist in the face of difficulties, children tended to respond to challenges in a positive manner (Pomerantz, Ng, and Wang 2006). These sorts of practices seem to be particularly important for children who hold negative, or disparaging beliefs about their own academic competencies, helping such 
children to avoid the frustration which often accompanies homework (Pomerantz, Grolnick, and Price 2005; Pomerantz, Ng, and Wang 2006). Such children also benefit when parents (again, mothers in the cited research) use techniques which support children's autonomy with their school and homework, e.g. not providing unasked for assistance, being supportive of effort and avoiding controlling language (Fei-Yin Ng, Kenney-Benson, and Pomerantz 2004; See also: Gonida and Cortina 2014).

When parents value education and learning for their own sake, children are likely to mirror these constructions (Gonida and Cortina 2014); when parents introduce external rewards for learning, and seek to control children’s learning (use controlling language, for example), children are less likely to be internally, intrinsically motivated to learn and achieve (Fan, Williams, and Wolters 2012). Moreover, children who see tasks as valuable are more likely to adapt their actions toward completion of those tasks, and to be better able to seek help with the tasks as needed (Du, Xu, and Fan 2016).

\section{Parental Self concept and supporting homework}

Parents engage with their children's learning within their own understanding of their role as parents, that is, what is they, as parents, should do, and, importantly, how they can impact on and support their children’s learning \{Hoover-Dempsey, 2005 \#18155\}. This, in turn, impacts on how parents engage with their children's schoolwork, and, for our purposes, how parents engage with homework. Research has shown, as well, that students construct their own beliefs about schooling, and their own understandings of themselves in relation to learning, in relation to the views their parents espouse and act out (Fan, Williams, and Wolters 2012). This self-understanding and self-belief hold great importance for students, as even students who are capable of doing well, can fail if they do not believe in their capabilities (Fan, Williams, and Wolters 2012) 
Walker et al found that some parents constructed their role around a belief that parents and schools were jointly responsible for children’s learning (Walker et al. 2005a), such joint responsibility may be easier to establish and work through where parents and staff share social and cultural capital. It is also worth noting that role construction is not fixed, but is malleable; parents' views of their roles in relation to the learning of their children can be and often is influenced by their relationships with school staff, and with what the school communicates to parents (Park and Holloway 2018).

There is a good deal of literature about 'parental role construction' which 'may best be defined as parents' beliefs about what they should do in relation to the child's education' (Walker et al. 2005b, , 89). As previous research has shown (Hoover-Dempsey and Sandler 1997), role construction effects how parents interact with their children's learning, how they get involved and what they do in terms of that involvement.Parents' understandings of their roles in relation to their children's learning help to determine what parents will then go on to do, and impacts on children's outcomes because parents then act on those understandings (Walker et al. 2005b). Parents' understanding of their role in their children's learning, their beliefs about how effective they will be doing this, and parental understanding of how open the school is to their contributions, all have an effect on whether or not parents become involved in their children’s learning (Hoover-Dempsey and Sandler 2005).

Moe et al (2018) found that parents who are motivated by a sense of autonomy, that is, they become involved with their children's learning out of a desire to be involved, rather than a sense of duty or obligation, are more likely to support autonomous attitudes in their children; this was labelled as ‘motivational scaffolding'. While most parents would agree that one goal of raising children is to produce, in the long run, an independent adult, in this sort of motivational support, parents are actively seeking to help children take responsibility 
for their own learning. (This again raises the issue of whether or not parents should be responsible for the oversight of children's homework, as mentioned above).

Carmichael and MacDonald (2016) found that parents with lower expectations of their children’s abilities were more likely to directly intervene, or help directly with homework than parents who had high expectations. Children are more likely to be motived toward homework if their parents support them by assuring the child that she can overcome difficulties and if the relevance of undertaking the homework is explained to the child (Madjar, Shklar, and Moshe 2016)

\section{Homework for mastery}

Taken together, all of the above argues that parents' involvement in homework is most likely to be beneficial when it supports children's and young people's self concept as learners, their autonomy toward their work, and their interest in and enjoyment of learning (Stables et al. 2014).

It seems that what is important is not that children and young people spend time on homework (which has little correlation to achievement), but rather that they are engaged in the learning taking place, 'the extent and quality of student engagement while doing the tasks’ (Madjar, Shklar, and Moshe 2016, , 174). Homework which students deem as concrete, and which supports them to be able ready to learn, or reinforces learning, also seems to be of greater value than homework which does not (Hallam 2006). It is important that both parents and school staff emphasise mastery orientations (Madjar, Shklar, and Moshe 2016); this is an extension of the classroom focus on mastery out into the home (and beyond). Tis can be particularly important for students who otherwise are thought (by themselves and others) to have low levels of competence in school work (Pomerantz, Ng, and Wang 2006) We might, then, define homework for mastery as 'tasks assigned to students by school teachers that are meant to be carried out during non-school hours, which support children's 
acquisition and embedding of mastery orientations'. Homework for mastery will have a principle aim of increasing the skills and attitudes that support young people's learning: autonomy, motivation and engagement.

This cannot, however, be accomplished by young people alone: it requires schools to reconsider the aim and assignment of homework tasks, and to realign those tasks to mastery orientations. It also requires schools to explain these changes to young people and their parents, and, in the best case scenario, to create new homework tasks together. Parents, as well, need to concentrate on the types of support more likely to engender and strengthen these orientations.

Figure 1 presents an illustration of the elements of homework for mastery, bringing these concepts together.

Figure 1 near here

\section{The principle of subsidiarity}

One of the parental attributes listed in . Figure 1is 'subsidiarity’. This may seem surprising, as it is more usually to be found in studies of organisational structures, policy on European relations and theology (Gosepath 2005; Melé 2005; Lenaerts 2017; Van Til 2008; McIlroy 2003). In essence, the concept means that actions should be undertaken at the lowest appropriate level. To put it in terms most often used around the development of toddlers, 'If I can do it, let me do it'. To give another example, a manager may dictate that a window display in a department store should change with the seasons, but the manager will not be directly involved in the choice of garments to display. In educational terms, we are more used to the concept (if not the term) in relation to the distribution of duties in a school (or of 
leadership); a head teacher may set the direction for the school but is not (general) involved in the details of individual teachers’ planning and classroom practice.

As Gosepath points out, 'It is an important, if not the most important, responsibility of the bigger institution to enable the smaller one to perform its tasks and to provide it with any necessary support' (Gosepath 2005, , 157). In applying this concept to homework, the principle of subsidiary would seem to operate in two areas - in relations between the school and families and in relations between parents and children.

I suggest that the principle of subsidiarity means that parents should not generally offer help that the young person has not requested. In Pomerantz' study this unasked for assistance was particularly unhelpful for young people who already held negative views of their abilities; these young people experience 'more depressive symptoms over time' than young people with more positive understandings of their abilities (Pomerantz, Ng, and Wang 2006, , 100). On the other hand, parents allowing young people to take the initiative led to increased feelings of competence among those young people (Rogers et al. 2014).

While it is obviously a school's remit to set (and if appropriate, mark) homework, the principle of subsidiarity would suggest that the more autonomy which can be given to families around how that homework should be carried out, the better. For example, families have reported having issues around time for homework (Patall, Cooper, and Robinson 2008) and have suggested they have more time at weekends (Epstein and Van Voorhis 2001), so this would mean that it would be better to set at least some homework to be handed in on Mondays. Homework can also be designed to call on skills parents already possess (rather than, for instance, assuming subject or content knowledge). This, then requires schools to know their parental cohorts (Goodall 2017b). The differences between families and their circumstances also need to be taken into account, so that children from families in poverty are 
not penalised by work set \{Mazzoli Smith, $2016 \# 23603$ \}. Thus, the concept of subsidiarity supports the autonomy of young people as well as their families.

\section{Parental Engagement in Homework for Mastery}

Parents’ mastery-oriented practices may manifest themselves in a variety of forms, with the underlying theme being aiding children in developing their competencies. (Pomerantz, Ng, and Wang 2006, , 100).

The framework proposed (see Figure 1Error! Reference source not found.) highlights three essential elements of homework for mastery, based on the literature. The first is the role of the school, as school staff are those who, for the very greatest part, generate and assign homework. The second element is the amalgamation of parental attributes and actions which will support the third and ultimate element, student outcomes.

\section{Parental attributes for mastery}

One of the reasons that parental engagement in homework can be beneficial is precisely because it signals to children that parents are interested in what they are doing, and value time spent on learning (Patall, Cooper, and Robinson 2008; Harris and Goodall 2008).

Parents can support their children’s learning in a myriad of ways that don't depend on checking homework (even if this is what many parents feel is the main purpose of engagement with children’s learning (Goodall and Montgomery 2013a; Harris and Goodall 2008). Simply showing an interest what young people are doing is likely to be effective (Epstein and Van Voorhis 2001), even at secondary level (OECD 2012), and showing young people the value of learning, valuing school work is also beneficial (Epstein and Van Voorhis 2001) all of which is likely to help young people to develop a positive outlook about their school work (Cooper, Lindsay, and Nye 2000) 
As we have seen above, for the most part, parental engagement in children's learning is considered beneficial; however, the picture in relation to parents' engagement in homework per se (as opposed to more general learning in the home) is more mixed. In contrast to the main run of parental engagement in children's learning, particularly that learning which takes place away from school, the literature is more divided about the impact of parents' engagement with homework. Some studies have found that such engagement has little effect; others have found that it can have a negative effect on children and this involvement seems to become more problematic as children age (Chowa, Masa, and Tucker 2013; Cooper, Lindsay, and Nye 2000); other research shows that this engagement can have more impact as children age (Núñez et al. 2015). Parental controlling actions (dictating schedules, giving unasked for advice) are negatively related to children’s outcomes (Núñez et al. 2015); however, this may be due to children who are struggling in school needing more parental direction and help (Cooper, Lindsay, and Nye 2000), rather than being a simple byproduct of parental actions. Other reviews of the literature show definite positive effects of parental engagement in homework, including students' views of their abilities in relation to learning (Rogers et al. 2014; Kurt and Taş 2019). Taken as a whole, research suggests strongly that when parents are appropriately, helpfully involved in children’s homework, children do more of that homework and benefit more from the learning involved, in terms of achievement, confidence, life skills (time management, self-regulation) and academic selfconcept (Núñez et al. 2015).

When parents are overly controlling, when they concentrate on achievement over learning, when they help when not needed or requested to do so, it's possible that they are preventing their children from attaining orientations toward autonomy and mastery (Rogers et al. 2014; Pomerantz, Ng, and Wang 2006). Parents offering help which children have not requested has been linked to depressive symptoms in children who already held negative 
views of their ability. Eccles found that 'excessive parental control is linked to lower intrinsic school motivation, to more negative changes in self esteem... to more school misbehaviour, and to relatively greater investment in peer social attachments' for student moving between elementary and junior high school (approximate 12 - 13 years old) (Eccles et al. 1991, , 66). Parents being overly controlling 'may deprive children of feeling they are autonomous, effective agents (Rogers et al 2014 pg 174). Such suppression of feelings of autonomy could have further ramifications for young people, particularly during the years of secondary education, when they are already negotiating their own status as independent agents. Put simply, the literature shows that parental support with homework is likely to be beneficial, parental control of homework is much more likely to be problematic. Kurt makes this distinction; while advocating for greater parental investment in homework, this is seen as supporting deep learning, motivation and autonomy, (rather than simply helping with content) (Kurt and Taş 2019).

When young people see homework activities as valuable, and are interested in what they have been asked to do (Stables et al. 2014), they are more likely to use 'adaptive selfregulation strategies' (Du, Xu, and Fan 2016, , 30). It would seem that what is important is not just the fact of doing (or assigning, or helping with) homework, or spending a lot of time on homework (in spite of the seemingly endless hours devoted to it), 'but, rather, the extent and quality of student engagement while doing the tasks’ (Madjar, Shklar, and Moshe 2016, , 174). This will have all the more impact when supported by parental actions which support mastery orientations, (rather than being controlling) and when parents help their children to believe in their own abilities to achieve. (Kurt and Taş 2019)

Parents' views of and toward homework are an obvious influence on their children, and, for our purposes, on children's role constructions in relation to learning and homework. Parents can support children by showing the value of homework (and showing that they 
themselves value learning), and by supporting children's academic self-concepts, for example in telling children that they are able to overcome difficulties (Madjar, Shklar, and Moshe 2016).

What is important, then, is not just that parents are engaged in children’s homework, but how they are engaged in that homework. Parental engagement in homework is most beneficial to students when it supports children's autonomy (for example, parents help children create a schedule for doing homework rather than imposing one), when it supports children's beliefs in their academic ability (for example, when parents praise effort and support children to overcome difficulties) and when parents support mastery views in children (when parents concentrate on learning, (what the child has learned) rather than on achievement (the marks gained by the child)); this orientation toward school work can support children’s growing confidence and help them face challenges (Núñez et al. 2015; Pomerantz, Ng, and Wang 2006).

\section{The role of the school}

To accomplish this end, it will be necessary to overcome the 'more is better' attitude toward homework - an attitude which may well be shared by families and teachers. Schools undertaking changes around homework would be well advised to do so in partnership with parents, involving them in the process from the outset, rather than merely informing them of the change. This simply parallels what teachers already know and do in relation to around young people 's learning; ideas are illustrated and explained by examples. In fact, the way teachers relate to homework - how it is valued, marked, etc, - has been shown again to contribute to students’ mastery orientations \{Tas, 2016 \#23664\}. It is essential that homework is not only assigned by the school staff, but that clear explanations are given to both students and parents as to the purposes and proposed outcomes of such activities, and that these are based on a clear understanding, in the first instance, by school staff of what 
homework tasks are meant to accomplish (Department of Education 2018). This paper argues, then for a joined up approach, so that the support for mastery orientations already present in classrooms is extended to homework and how it is presented.

'Appropriate homework' has two levels - appropriate to the aim of the work, and appropriate to the student. In the first instance, the homework assignment must be appropriate to the aim, that is, it must have a fighting chance of fulfilling the stated aim. It is important that both the students and their parents, as well as the teaching staff, know this aim and how the task relates to it: how else will it be possible to know if the homework has been effective?

Secondly, the homework must be appropriate for the young people who are to undertake it (Kay et al. 1994). This means careful consideration of what the young people in general are able to accomplish. As has been noted above, assigning homework on the understanding (or hope) that family members can supply content or subject knowledge is likely to widen the gap between children from different backgrounds, as not all parents may be able to supply this help (Epstein and Van Voorhis 2001; Cooper, Lindsay, and Nye 2000).

We have noted that marking and assessment takes up a great deal of teachers' time and often ranks among the activities listed as most problematic by them. Indeed while the activity is 'vital', when poorly done it can be 'demoralising and a waste of time for teachers and pupils alike' (Independent Teacher Workload Review Group 2016, , 5). What this paper argues is that homework should only be assigned if it is likely to be effective in supporting young people’s mastery orientations to their work.

\section{Scaffolding parental engagement in homework for mastery}

What is it then, that parents need to do - and be supported to do, in relation to their children's homework? 
There is no one, simple answer to this - as there is no one, simple answer to almost any question in relation to the learning of such a vast array of people (Crozier 1999; Crozier 2001; Goodall 2017b; Goodall 2019). However, there are indications of practices which have been shown to be beneficial and to support children to have belief in their ability to achieve, and to have the skills and attitudes which will help them to do so (Medwell and Wray 2019), as noted above, these are supports for mastery orientations. This paper does not argue for a simple, applicable-to-all approach, due to the complexity of family life and of families.

There is still a great deal that could be investigated by further research. The new definition of homework offered above should be tested, preferably throughout the age range and phases of schooling. Interventions to support homework for mastery exist but the support for parents is often lacking; it would be useful for future research to include parental support as an integral element of both interventions and their evaluation.

These practices include encouraging children to work out problems on their own, and putting the emphasis around homework on the learning rather than on achievement , as well as encouraging children to keep going when they face difficulties (Pomerantz, Ng, and Wang 2006)

The research discussed above makes it clear that the greatest value of parents' engagement with learning will come from providing support in the more amorphous, more subtle (Jeynes 2012; Jeynes 2014) less content specific way of providing moral support and interest in learning. This paper advances theory in the field, by offering new, clearer definitions and advocating increasing parental support for mastery orientations, support for autonomy, self-regulation, self-belief, in short for the attitudes and skills which will support learning and self belief in the long run for students. 
Acknowledgement: The author is grateful to Dr. Shona McIntosh, University of Bath, for her comments and suggestions on the text of this article., and to the reviewers whose careful and constructive suggestions have improved this paper. 
Baker, Clare, David Dawson, Tim Thair, and Rachel Youngs. 2014. "Longitudinal study of young people in England: cohort 2, wave 1: November 2014." In. London: Department for Education

Bas, Gokhan, Cihad Senturk, and Fatih Mehmet Cigerci. 2017. "Homework and academic achievement: A meta-analytic review of research." Review of. Issues in Educational Research 27 (1):31.

BBC News Online. 2012. "Michael Gove scraps government homework guidelines." BBC News.

Borgonovi, F. , and G. Montt. 2012. "Parental Involvement in Selected PISA Countries and Economies." In Education Working Papers. OECD.

Carmichael, Colin, and Amy MacDonald. 2016. "Parental influences on primary school children's mathematics achievement: insights from the Longitudinal Study of Australian Children." Review of. Education 3-13 44 (2):197-211.

Chowa, Gina AN, Rainier D Masa, and Jenna Tucker. 2013. "The effects of parental involvement on academic performance of Ghanaian youth: Testing measurement and relationships using structural equation modeling." Review of. Children and Youth Services Review 35 (12):202030.

Cobb-Clark, Deborah A, Sonja C Kassenboehmer, and Mathias G Sinning. 2016. "Locus of control and savings." Review of. Journal of Banking \& Finance 73:113-30.

Cooper, Harris, James J Lindsay, and Barbara Nye. 2000. "Homework in the home: How student, family, and parenting-style differences relate to the homework process." Review of. Contemporary Educational Psychology 25 (4):464-87.

Cooper, Harris, Jorgianne Civey Robinson, and Erika A Patall. 2006. "Does homework improve academic achievement? A synthesis of research, 1987-2003." Review of. Review of Educational Research 76 (1):1-62.

Corno, Lyn, and Jianzhong Xu. 2004. "Homework as the job of childhood." Review of. Theory into practice $43(3): 227-33$.

Coutts, Pamela M. 2004. "Meanings of Homework and Implications for Practice." Review of. Theory into practice 43 (3):182-8. doi: 10.1207/s15430421tip4303_3.

Crozier, G. . 2001. "Excluded Parents: the deracialisation of parental involvement " Review of. Race Ethnicity and Education 4 (4):329-41.

Crozier, Gill. 1999. "Is It a Case of "We Know When We're Not Wanted?" The Parents' Perspective on Parent-Teacher Roles and Relationships." Review of. Educational Research 41 (3):315-28.

Deci, Edward L, Richard Koestner, and Richard M Ryan. 2001. "Extrinsic rewards and intrinsic motivation in education: Reconsidered once again." Review of. Review of Educational Research 71 (1):1-27.

Department of Education. 2018. "Ways to reduce workload in your school(s)." In.

Desforges, Charles, and Alberto Abouchaar. 2003. "The impact of parental involvement, parental support and family education on pupil achievement and adjustment: A literature review." In. London: Department of Education and Skills.

Dewey, John. 2003. "My Pedagogic Creed." The informal education archives; First published in The School Journal, Volume LIV, Number 3 (January 16, 1897), pages 77-80., Accessed 18.01.03. http://www.users.globalnet.co.uk/ infed/e-texts/e-dew-pc.htm.

Du, Jianxia, Jianzhong Xu, and Xitao Fan. 2016. "Investigating factors that influence students' help seeking in math homework: A multilevel analysis." Review of. Learning and Individual Differences 48:29-35.

Eccles, Jacquelynne S, Christy Miller Buchanan, Constance Flanagan, Andrew Fuligni, Carol Midgley, and Doris Yee. 1991. "Control versus autonomy during early adolescence." Review of. Journal of Social Issues 47 (4):53-68.

Epstein, Joyce L. 1983. "Homework Practices, Achievements, and Behaviors of Elementary School Students." Review of. 
Epstein, Joyce L, and Frances L Van Voorhis. 2001. "More than minutes: Teachers' roles in designing homework." Review of. Educational Psychologist 36 (3):181-93.

Fan, Huiyong, Jianzhong Xu, Zhihui Cai, Jinbo He, and Xitao Fan. 2017. "Homework and students' achievement in math and science: A 30-year meta-analysis, 1986-2015." Review of. Educational Research Review 20:35-54.

Fan, Weihua, Cathy M Williams, and Christopher A Wolters. 2012. "Parental involvement in predicting school motivation: Similar and differential effects across ethnic groups." Review of. The Journal of Educational Research 105 (1):21-35.

Fan, Weihua, and Cathy M. Williams. 2010. "The effects of parental involvement on students' academic self-efficacy, engagement and intrinsic motivation." Review of. Educational Psychology 30 (1):53-74. doi: 10.1080/01443410903353302.

Fan, Xitao, and Michael Chen. 2001a. "Parental involvement and students' academic achievement: A meta-analysis." Review of. Educational Psychology Review 13 (1):1-22.

- - . 2001b. "Parental Involvement and Students' Academic Achievement: A Meta-Analysis." Review of. Educational Psychology Review 13 (1):1 - 22.

Fei-Yin Ng, Florrie, Gwen A Kenney-Benson, and Eva M Pomerantz. 2004. "Children's achievement moderates the effects of mothers' use of control and autonomy support." Review of. Child Development 75 (3):764-80.

Flunger, Barbara, Ulrich Trautwein, Benjamin Nagengast, Oliver Lüdtke, Alois Niggli, and Inge Schnyder. 2015. "The Janus-faced nature of time spent on homework: Using latent profile analyses to predict academic achievement over a school year." Review of. Learning and Instruction 39:97-106.

Freire, Isabel, and Ana Paula Viana Caetano. 2005. "Mediation devices in schools - from the class assemblies to the whole school. A multi-case study." Review of.:21.

Freire, P. 1970. Pedagogy of the oppressed. Translated by translated by Myra Bergman Ramos. London: Penguin Books.

Gonida, Eleftheria N, and Kai S Cortina. 2014. "Parental involvement in homework: Relations with parent and student achievement-related motivational beliefs and achievement." Review of. British Journal of Educational Psychology 84 (3):376-96.

Goodall, J. 2017a. "Learning-centred parental engagement: Freire reimagined." Review of. Educational review 70 (5):1-19. doi: 10.1080/00131911.2017.1358697.

- - . 2019. "Parental engagement and deficit discourses: absolving the system and solving parents." Review of. Educational review:1-13. doi: 10.1080/00131911.2018.1559801.

Goodall, J., and C. Montgomery. 2013a. "Parental involvement to parental engagement: a continuum." Review of. Educational review:1-12. doi: 10.1080/00131911.2013.781576.

Goodall, Janet. 2017b. Narrowing the achievement gap: Parental engagement with children's learning: Routledge.

- - . 2018. "Learning-centred parental engagement: Freire reimagined." Review of. Educational Review 70 (5):603-21.

Goodall, Janet, and Sue Johnston-Wilder. 2015. "Overcoming Mathematical Helplessness and Developing Mathematical Resilience in Parents: An Illustrative Case Study." Review of. Creative Education 6 (05):526.

Goodall, Janet, and Caroline Montgomery. 2013b. "Parental involvement to parental engagement: a continuum." Review of. Educational Review (ahead-of-print):1-12.

Gosepath, S. 2005. "The Principle of Subsidiarity." In Real World Justice., edited by Follesdal A. and Pogge T. Dordrecht: Springer.

Grolnick, Wendy S, Corina Benjet, Carolyn O Kurowski, and Nicholas H Apostoleris. 1997. "Predictors of parent involvement in children's schooling." Review of. Journal of Educational Psychology 89 (3):538.

Hallam, Susan. 2006. "Homework: its uses and abuses." Review of. London: Institute of Education:110. 
Harris, A, and J Goodall. 2008. "Do parents know they matter? Engaging all parents in learning." Review of. Educational Research 50 (3):277 - 89.

Higton, John, Sarah Leonardi, Arifa Choudhoury, Neil Richards, David Owen, and Nicholas Sofroniou. 2017. "Teacher workload survey 2016." In.

Hoover-Dempsey, K.V., and H.M. Sandler. 1997. "Why do parents become involved in their children's education?" Review of. Review of Educational Research 67 (1):3-42.

Hoover-Dempsey, Kathleen V, and Howard M Sandler. 2005. "Final performance report for OERI Grant\# R305T010673: The social context of parental involvement: A path to enhanced achievement." Review of.

Independent Teacher Workload Review Group. 2016. "Eliminating unnecessary workload around marking " In. London: Gov.UK.

Jeynes, W. 2012. "A Meta-Analysis of the Efficacy of Different Types of Parental Involvement Programs for Urban Students." Review of. Urban Education 47 (4):706-42. doi: $10.1177 / 0042085912445643$.

Jeynes, W. H. 2005. "A meta-analysis of the relation of parental involvement to urban elementary school student academic achievement." Review of. Urban Education 40 (3):237.

- - . 2007. "The relationship between parental involvement and urban secondary school student academic achievement: A meta-analysis." Review of. Urban Education 42 (1):82.

Jeynes, William H. 2014. "Parental Involvement That Works ... Because It's Age-Appropriate." Review of. Kappa Delta Pi Record 50 (2):85-8. doi: 10.1080/00228958.2014.900852.

Kay, Pamela J, Martha Fitzgerald, Carol Paradee, and Amy Mellencamp. 1994. "Making homework work at home: The parent's perspective." Review of. Journal of Learning Disabilities 27 (9):550-61.

Komarraju, Meera, and Dustin Nadler. 2013. "Self-efficacy and academic achievement: Why do implicit beliefs, goals, and effort regulation matter?" Review of. Learning and Individual Differences 25:67-72.

Kurt, Uluhan, and Yasemin Taş. 2019. "Prediction of students' strategies for doing science homework by parental support and students' goal orientation." Review of. Pegem Egitim ve Ogretim Dergisi= Pegem Journal of Education and Instruction 9 (2):585.

Ladson-Billings, Gloria. 2006. "From the achievement gap to the education debt: Understanding achievement in US schools." Review of. Educational Researcher 35 (7):3-12.

Lenaerts, Koen. 2017. "The principle of subsidiarity and the environment in the European Union: keeping the balance of federalism." In European Environmental Law, 129-78. Routledge.

Madjar, Nir, Nitzan Shklar, and Limor Moshe. 2016. "The role of parental attitudes in children's motivation toward homework assignments." Review of. Psychology in the Schools 53 (2):173-88.

Mcllroy, David. 2003. "Subsidiarity and sphere sovereignty: Christian reflections on the size, shape and scope of government." Review of. Law \& Just.-Christian L. Rev. 151:111.

Medwell, Jane, and David Wray. 2019. "Primary homework in England: the beliefs and practices of teachers in primary schools." Review of. Education 3-13 47 (2):191-204.

Melé, Domènec. 2005. "Exploring the principle of subsidiarity in organisational forms." Review of. Journal of Business Ethics 60 (3):293-305.

Moè, Angelica, Idit Katz, and Marianna Alesi. 2018. "Scaffolding for motivation by parents, and child homework motivations and emotions: Effects of a training programme." Review of. British Journal of Educational Psychology 88 (2):323-44.

NASUWT. 2018. "The Big Question." In.: NASUWT.

Núñez, José Carlos, N Suárez, Pedro Rosário, G Vallejo, A Valle, and Joyce L Epstein. 2015.

"Relationships between perceived parental involvement in homework, student homework behaviors, and academic achievement: differences among elementary, junior high, and high school students." Review of. Metacognition and learning 10 (3):375-406.

OECD. 2012. "PISA - Let's Read Them a Story! The Parent Factor in Education." In.: OECD Publishing. 
Ofsted. 2018. "Ofsted Parents' Panel Annual Report." In.: OFSTED.

Organisation for Economic Co-operation, Development. 2014. Does homework perpetuate inequities in education? : OECD Publishing.

Organisation for Economic Co-operation Development. 2011. Quality time for students: learning in and out of school: OECD.

- - - 2013. "PISA 2012 results: What Makes Schools Successful? Resources, Policies and Practices (volume IV)." In.: OECD Publishing Paris, France.

Park, Sira, and Susan Holloway. 2018. "Parental Involvement in Adolescents' Education: An Examination of the Interplay among School Factors, Parental Role Construction, and Family Income." Review of. School Community Journal 28 (1):9-36.

Patall, Erika A, Harris Cooper, and Jorgianne Civey Robinson. 2008. "Parent involvement in homework: A research synthesis." Review of. Review of Educational Research 78 (4):1039101.

Peters, Mark, Ken Seeds, A Goldstein, and N Coleman. 2008. "Parental involvement in children's education 2007." In. London: Department for Children, Schools and Families.

Pomerantz, Eva M, Wendy S Grolnick, and Carrie E Price. 2005. "The role of parents in how children approach achievement." Review of. Handbook of competence and motivation:259-78.

Pomerantz, Eva M, Florrie Fei-Yin Ng, and Qian Wang. 2006. "Mothers' mastery-oriented involvement in children's homework: Implications for the well-being of children with negative perceptions of competence." Review of. Journal of Educational Psychology 98 (1):99.

Pressman, Robert M, David B Sugarman, Melissa L Nemon, Jennifer Desjarlais, Judith A Owens, and Allison Schettini-Evans. 2015. "Homework and family stress: With consideration of parents' self confidence, educational level, and cultural background." Review of. The American Journal of Family Therapy 43 (4):297-313.

Rogers, Maria, Clarisa Markel, Jonathan D Midgett, Bruce A Ryan, and Rosemary Tannock. 2014. "Measuring children's perceptions of parental involvement in conjoint behavioral consultation: Factor structure and reliability of the Parental Support for Learning Scale." Review of. Assessment for Effective Intervention 39 (3):170-81.

Sammons, P., K Sylva, E.C. Melhuish, B. Taggart, K Toth, and B Smees. 2014. "Influences on students' GCSE attainment and progress at age 16." In.: Department of Education

Save the Children. 2013. "Too Young to Fail." In. London: Save the Children.

Stables, Andrew, Kyoko Murakami, Shona McIntosh, and Susan Martin. 2014. "Conceptions of effort among students, teachers and parents within an English secondary school." Review of. Research Papers in Education 29 (5):626-48.

Trautwein, Ulrich. 2007. "The homework-achievement relation reconsidered: Differentiating homework time, homework frequency, and homework effort." Review of. Learning and Instruction 17 (3):372-88.

Van Til, Kent A. 2008. "Subsidiarity and Sphere-Sovereignty: A Match Made in...?" Review of. Theological Studies 69 (3):610-36.

Van Voorhis, Frances L. 2004. "Reflecting on the Homework Ritual: Assignments and Designs." Review of. Theory into practice 43 (3):205-12. doi: 10.1207/s15430421tip4303_6.

Varkey Foundation. 2017. "Global Parents' Survey." In. London: Varkey Foundation.

Vincent, C., and S. Tomlinson. 1997. "Home-School Relationships: 'the Swarming of Disciplinary Mechanisms'." Review of. British Educational Research Journal 23 (3).

Vincent, Carol. 2001. "Social class and parental agency." Review of. Journal of Education Policy 16 ( 4):347-64.

Walker, Joan M. T., Andrew S. Wilkins, James R. Dallaire, Howard M. Sandler, and Kathleen V. Hoover-Dempsey. 2005a. "Parental Involvement: Model Revision through Scale Development." Review of. The Elementary School Journal 106 (2):85-104. 
Walker, Joan MT, Andrew S Wilkins, James R Dallaire, Howard M Sandler, and Kathleen V HooverDempsey. 2005b. "Parental involvement: Model revision through scale development." Review of. The Elementary School Journal 106 (2):85-104.

Warton, Pamela M. 2001. "The Forgotten Voices in Homework: Views of Students." Review of. Educational Psychologist 36 (3):155-65. doi: 10.1207/S15326985EP3603_2.

Xu, Jianzhong. 2010. "Homework purpose scale for high school students: A validation study." Review of. Educational and Psychological Measurement 70 (3):459-76.

- - . 2013. "Why Do Students Have Difficulties Completing Homework? The Need for Homework Management." Review of. Journal of Education and Training Studies 1 (1):98-105.

Xu, Jianzhong, and Lyn Corno. 2003. "Family help and homework management reported by middle school students." Review of. The Elementary School Journal 103 (5):503-17.

$\mathrm{Xu}$, Jianzhong, and Ruiping Yuan. 2003. "Doing Homework: Listening to Students,'Parents,'and Teachers' Voices in One Urban Middle School Community." Review of. School Community Journal 13 (2):25.

i 'Parents' should be understood to include all adults with a caring responsibility for the child, in or out of a family group.

${ }^{\text {ii }}$ It is interesting that these figures do not align with the figures given by students about how much time they spend on homework.

iii And also evaluated effectively, to show if those outcomes are being achieved.

${ }^{\text {iv }}$ While it is true that there are an increasing number of opportunities for young people to do this work on the school grounds - after school homework clubs for example, this article concentrates on work assigned by school staff to be completed outside of school hours and most usually in the students' home. 